\title{
"Planificación estratégica: instrumento de desarrollo local para fortalecer el turismo rural en Tierras Altas, Chiriquí, Panamá".
}

\author{
Rosa Mora ${ }^{1 *}$ \\ ${ }^{1}$ Facultad de Administración de Empresas y Contabilidad, Universidad de Panamá. \\ *Autor para correspondencia. E-mail: Profa.rosamora@gmail.com
}

Recibido: 24 de octubre de 2019

Aceptado: 12 de noviembre de 2019

\begin{abstract}
Resumen
La finalidad de este artículo es presentar algunos resultados que surgen de una investigación llevada a cabo en el Distrito de Tierras Altas; en donde hemos hecho un recuento sobre algunos hitos que han incidido en el planeamiento del turismo, y sobre esta base, realizado un diagnóstico participativo, en donde se evalúan los recursos y atractivos turísticos, la planta turística, los servicios ofrecidos, la percepción de la experiencia de viaje y el nivel de organización de las comunidades. La actividad turística en Panamá ha crecido considerablemente en las últimas dos décadas, observable en las estadísticas de llegadas y gasto turístico de visitantes internacionales. Esta situación ha llevado a despertar interés por el estudio y planificación del turismo en el país. En este sentido el espacio geográfico se constituye como soporte y recurso fundamental de la misma, siendo además factor de desarrollo y localización. (Guzmán y Fernández, 2002). Somos conscientes de que la actividad turística permite conocer y experimentar diferentes sensaciones, contribuye al intercambio cultural, a la diversificación económica y a la puesta en valor de los recursos de cada comunidad, pero es en ese proceso de valorización de recursos, donde la comunidad anfitriona debe ser protagonista y generadora de su propio desarrollo. La planificación estratégica parte de la necesidad de integración del turismo con otras actividades, la que trata de maximizar los beneficios del sector, a la vez que minimiza el riesgo ambiental, cultural y social. El aspecto fundamental de esta planificación surge de la necesidad de abordar el proceso desde el involucramiento del mayor número posible de agentes sociales y económicos.

Palabras clave: Planeamiento turístico, planificación estratégica, desarrollo turístico, diagnostico participativo, comunidad anfitriona, diversificación económica.
\end{abstract}

\footnotetext{
Abstract

The purpose of this article is to present some of the results obtained from an investigation performed in Distrito de Tierras Altas. We made a recount of some of the milestones by which the planning of tourism was effected, and from this basis a participative diagnostic has been made, evaluating resources and touristic attractions, planning, services offered, the perception of the
} 
experience from traveling there and the level of organization of the communities involved. Tourism activity in Panama has considerably evolved in the last two decades, as observed in the statistics of arrivals and tourism expenditures by visitors. This situation sparked the interest to perform this study and to have an effective tourism planning. In this sense, the geographic space turns into the fundamental support and resources of the activity, besides becoming a factor of development and localization. (Guzmán y Fernández, 2002). We are fully aware that tourism activities allow to gain knowledge and experiment different sensations, contributes to intercultural exchange, to economic diversification and to enhance the resources of each community, but it is in this process of giving value to the resources, the host community must be fully involved in generating and sustaining its own development. Strategic Planning is part of the need to integrate tourism with other activities, trying to maximize the benefits but minimizing the environmental, cultural and social risks. The fundamental aspect of this planning must be the need to integrate the process beginning with the involvement of the highest number of economic and social agents.

Keywords: Tourism Planning, touristic, planning, tourism development, participative diagnosis, host community, economic diversification.

\section{Introducción}

El recién creado distrito de Tierras Altas es un rico patrimonio histórico, cultural y natural que conserva una importante cultura precolombina de alto valor arqueológico, nacional e internacional, que junto a su pueblo trabajador configura un destino con gran potencial turístico. A partir de ello, hemos de impulsar diferentes acciones para lograr una propuesta sostenible, y así consolidar el desarrollo del turismo rural en las diversas comunidades que conforman el distrito.

Se realizaron talleres participativos, en los cuales se identificaron las fortalezas y debilidades, para luego analizar y diagnosticar oferta y demanda, y así definir el perfil del turista. Además, se hicieron entrevistas y se realizaron encuestas, permitiendo establecer la situación actual y orientando en la gestión de su potencial, por lo que se formulan estrategias para alcanzar el desarrollo turístico del destino, teniendo en cuenta la participación de la población local y la sostenibilidad.

Se recomienda un Plan de Acción, para proporcionar al referido distrito, de una herramienta que identifique la particularidad de sus atractivos turísticos, sus limitaciones, sus oportunidades de desarrollo y sus riesgos, entre otros factores, con la finalidad de impulsar un desarrollo turístico sostenible en sus comunidades.

$\mathrm{Al}$ respecto, Bernet (2005, p.220) explica que el objetivo de la planeación estratégica es estudiar la localidad turística, y que ésta logre conocer su potencial turístico, es construir un plan a seguir para invertir en la región que permita hacer de determinado lugar un destino turístico.

David, Fasabi (2014). Indica los beneficios del planeamiento estratégico, siendo estos lo siguientes:

- "Permite a una organización ser más proactiva que reactiva, ejerciendo control en la construcción de su futuro.

- Ayuda a las organizaciones a formular mejores estrategias, utilizando un enfoque más sistemático, lógico y racional.

- Genera oportunidades de efectiva interacción entre los involucrados. 
- Incentiva la participación en el proceso, siendo esta la clave para lograr la comprensión y compromiso con la organización, lo cual resulta necesario para generar el cambio.

- Propicia el empoderamiento a algunos responsables para fortalecer el sentido de eficacia, a ejercer iniciativa y reconocimiento de sus actividades. (Fasabi, 2014, p.40-41)."

Por su parte, Getz (1986, citado por Hall y Page, 1997, p.309), considera que "la planificación turística debe ser un proceso basado en estudios, investigaciones y análisis, que busque optimizar la contribución del turismo al bienestar social y a la conservación ambiental”.

Mientras que Acerenza (1997, p.49), manifiesta acerca de la planificación turística que uno de sus objetivos, precisamente el de captar divisas, fue uno de los más privilegiados en la planificación del turismo en Latinoamérica desde los años setenta, originando a lo que ahora se denomina como "enfoque de política económica." Y continúa señalando, en este contexto, lo siguiente:

"La política de desarrollo turístico dio por resultado una gran cantidad de planes de desarrollo que combinaban el enfoque urbanístico, es decir extensos inventarios de recursos con propuestas de zonificación atendiendo al impacto espacial de la actividad, con el enfoque económico que respondía a los impactos económicos: captar divisas, generar empleo y desarrollo regional". (Acerenza, 1997; citado por Varisco, 2007, p.18).

Comprendido el concepto, el primer paso de la planificación estratégica, según explicación de Garrido (2002), consiste en "informar a la población y, sobre todo, en promover y dinamizar su interés" en participar, aunque debemos reconocer que ciertos gremios y esferas sociales, generalmente los más excluidos, serán especialmente difíciles de convencer a participar. Además, o no se encuentran organizados o desarrollan mecanismos informales de estructuración colectiva.

Por esa razón sigue explicando Garrido que "la participación de estos actores se ha de plantear en consonancia con sus hábitos y costumbres, en sus espacios de convivencia y con técnicas que incorporen elementos de su sociabilidad para de esta forma acercar la planificación a sus espacios y características propias de vinculación social"' (Garrido, 2002).

Por tanto, la participación de la población local en el proceso de planificación puede ser directa a través de talleres, o indirecta a través de encuestas y/o entrevistas.

La planificación estratégica responde a "las incertidumbres turísticas de los mercados, adecuando las ofertas de productos turísticos" (Diez, 2011) del municipio, a las exigencias de la demanda. Sin embargo, el aspecto fundamental de este tipo de planificación en turismo es el de la necesidad de abordar el proceso desde el involucramiento del mayor número posible de actores locales.

En cuanto a esto, Arocena (1995, p.26) señala que “...los actores locales son simultáneamente motor y expresión del desarrollo local." Y ante esta definición, el autor los clasifica en: "a) actores ligados a la toma de decisiones (político-institucionales); b) actores ligados a técnicas particulares (expertos-profesionales); c) actores ligados a la acción sobre el terreno (la población y todas sus expresiones activas)" (Arocena, 1995, p.26). 
Por otro lado, la participación de la comunidad local es estratégica para poder desarrollar una propuesta turística, ya que sin el apoyo de los pobladores es muy difícil que se alcance a ejecutar un proceso de planificación exitoso. Para lograr un desarrollo turístico equilibrado y sostenible, se requiere considerar las aspiraciones de la población local, teniendo en cuenta los valores, ideales e identidades.

Paul Samuel (1987), la planificación estratégica, tiene como pilar fundamental el concepto de participación, siendo esta entendida como “...un proceso activo por el cual los beneficiarios o grupos comunitarios pueden influir en las orientaciones y en la dirección de proyectos de desarrollo que se realizan en su beneficio".

La participación puede ser entendida como un medio o como un fin, no siendo éstas mutuamente excluyentes una de la otra, debido a que la participación como un medio, es entendida como un proceso en el cual la población local participa en los programas de desarrollo para ajustarlos a la realidad y lograr su ejecución. Es decir que aquí la participación se presenta como un medio para poder implementar los programas de desarrollo diseñados desde una realidad externa a la de la comunidad local. Por otro lado, la participación como un fin, es cuando "se genera un empoderamiento de la población local, al adquirir capacidades y conocimientos, que le permiten obtener mayores responsabilidades en la gestión del proceso de desarrollo" (Morales, 2016).

Cuando se llevan a cabo gestiones de desarrollo local, se necesita del diálogo y participación de los actores locales, así como de la colaboración de las instituciones y organizaciones; pero principalmente es necesario un compromiso público-privado en cuanto al logro de los objetivos para alcanzar el desarrollo. En cuanto a ello, el sentido conceptual de participación ciudadana es importante para lograr cambios positivos en el espacio, organizar las actividades productivas y así, poder participar con éxito en el mundo globalizado.

\section{Antecedentes}

Las investigaciones precedentes en la región han dejado en evidencia los problemas con que cuenta, tales como las inclemencias climatológicas, desempleo, actitud migratoria, escasa sensibilización de la población y de los visitantes por el cuidado de su patrimonio, entre otros; además de que la información sobre la actividad turística local carece de estructura y confiabilidad.

Este trabajo busca fundamentar las posibilidades que puede brindar el turismo, como una herramienta que colabore con el desarrollo local en el distrito de Tierras Altas; y e pretende ser un aporte para una zona muy rica, desde la óptica de los atractivos turísticos, pero a la vez muy pobre en los aspectos relacionados a la planificación.

Los pobladores han manifestado que anteriormente no estaban preparados para recibir turismo y que se sentían "invadidos" por una demanda, vista como una amenaza más que como una oportunidad de desarrollo. Pero que han logrado superarlo dando los primeros pasos como destino turístico a partir de una visión compartida por la comunidad. 
Por ende, las localidades del distrito de Tierras Altas inicialmente no estuvieron una visión común, consensuada y compartida, sino que se dieron respuestas individuales, según se iban dando las circunstancias.

Es así como sin una planificación anticipada y coordinada surgieron algunos emprendimientos visionarios como "El Mirador", Hotel Bambito, Finca Janson, Arte Cruz, Finca Palo Santo, etc. Que lograron despegar. Pero, que también fueron muchos los que murieron en su cuna.

Ahora han logrado entender que sus comunidades son atractivos de visitantes nacionales y extranjeros que quieren escapar de la ciudad y del calor, ser testigos de un paisaje volcánico verde y exuberante; y de muchos aventureros que desean escalar el Volcán Barú, hacer rafting, bañarse en aguas termales o en frescos ríos, etc. y que esto representa ingresos económicos y que a través de estos ingresos está la posibilidad de mejorar su calidad de vida.

\section{Materiales y métodos}

Para realizar la investigación recurrimos a hacer uso de diversos métodos y técnicas tales como:

Método descriptivo: Es muy adecuado para el desarrollo de proyectos, ya que con el mismo se busca “...especificar las propiedades importantes de personas, grupos, comunidades o cualquier otro fenómeno que sea sometido a análisis. Mide o evalúa diversos aspectos, dimensiones o componentes del fenómeno a investigar (HERNÁNDEZ SAMPIERI, 1997). Con este método se logró especificar elementos sustanciales para analizar la situación de forma integral permitiendo diseñar una propuesta innovadora.

Método explicativo: “...se utiliza con el fin de intentar determinar las causas y consecuencias de un fenómeno concreto.” (CASTILLERO MIMENZA, 2017). Con este método se identifican las falencias con las que cuenta el distrito. Se realizó un diagnóstico de la localidad para tener un sustento viable del escenario; y de allí partir a formular una propuesta que fomente el desarrollo del distrito, en armonía con los aspectos económicos, sociales y ambientales, ya que a través del manejo de datos y su estudio, se argumenta la necesidad de planificar el desarrollo del sector, teniendo un marco estratégico base para la elaboración de la propuesta, siempre con la visión de fomentar el desarrollo turístico local.

Se procede a hacer un diagnóstico participativo y un levantamiento de datos a través de los diferentes métodos de instrumentación, siendo estos las entrevistas y encuestas a turistas y talleres de evaluación a pobladores (HERNÁNDEZ SAMPIERI et all., Íbidem). Se empleó una muestra aleatoria simple de 150 visitantes que decidieron colaborarnos anunciándoles oportunamente que la información suministrada sería utilizada exclusivamente para asuntos académicos.

Igualmente, se realiza en campo un inventario de los recursos y atractivos que hacen de la zona un lugar especial para el turismo. También se realiza la evaluación de los factores internos y externos que repercuten en la actividad turística del distrito, a través de una matriz "FODA" en donde se plantean los objetivos estratégicos (STEINER, 2014). 
De allí surge la propuesta, en su completo detalle, dividido en programas, y estos en proyectos de diversa índole, para el mejoramiento del municipio de Tierras Altas en materia de infraestructura, capacitación a la población, desarrollo local y su divulgación.

\section{Resultados}

Los resultados para cada ítem abordado en la encuesta, fueron los siguientes:

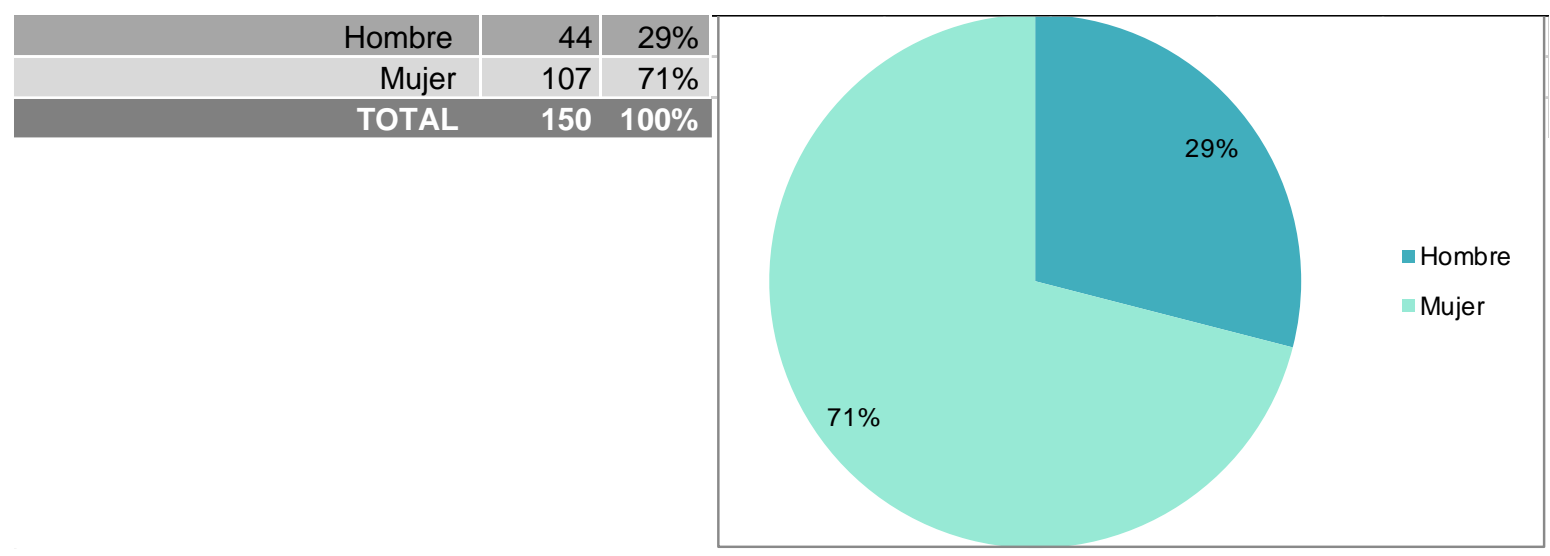

Gráfica N¹: Género del encuestado.

Fuente: Diseñado por la autora.

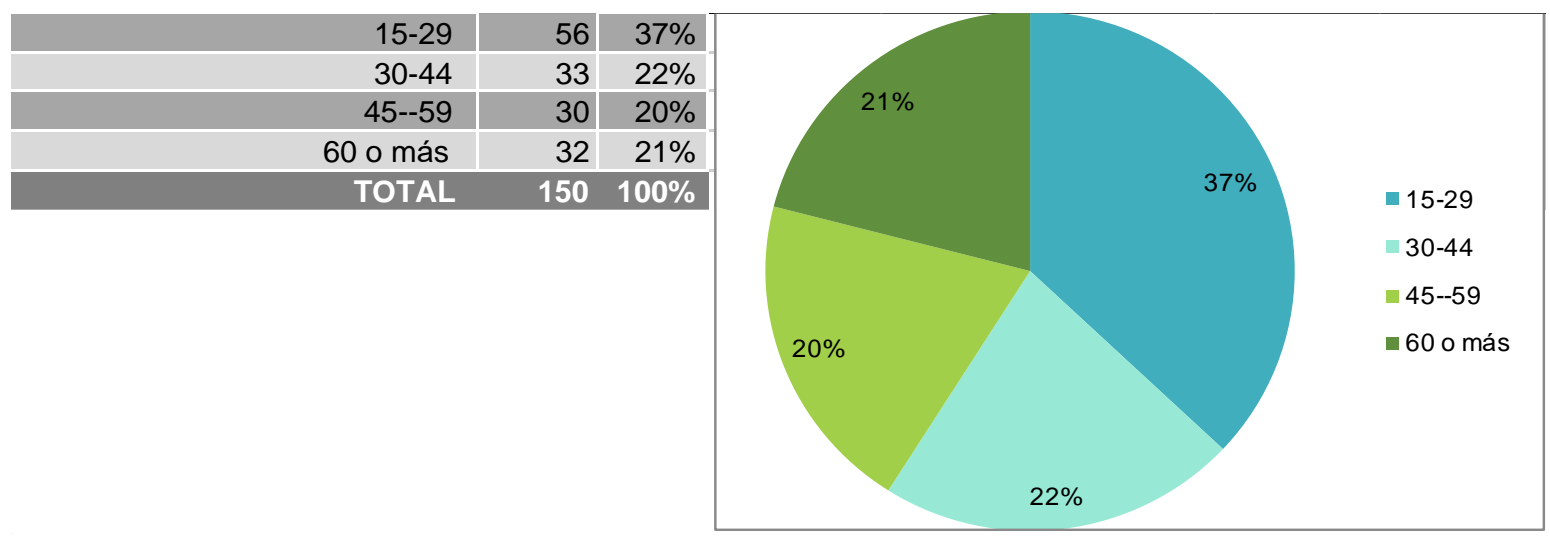

Gráfica No2: Edad del encuestado.

Fuente: diseñado por la autora. 


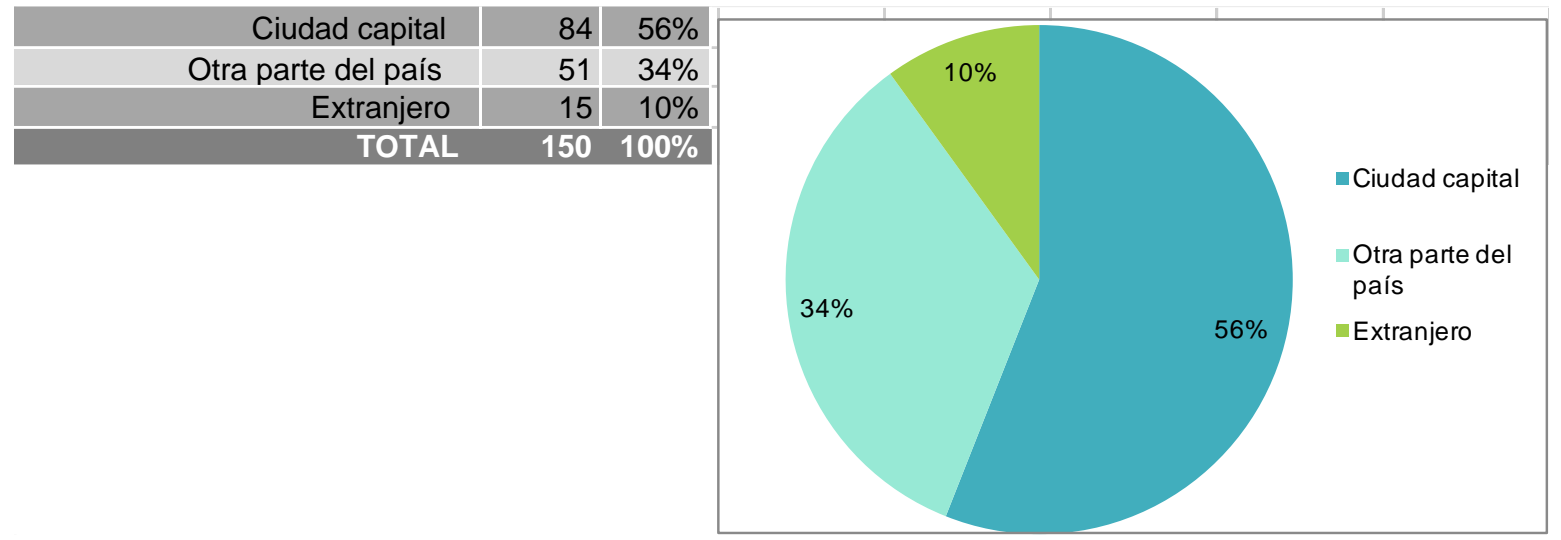

Gráfica $\mathbf{N}^{\mathbf{0}} 3$ : Lugar de procedencia del encuestado.

Fuente: diseñado por la autora.

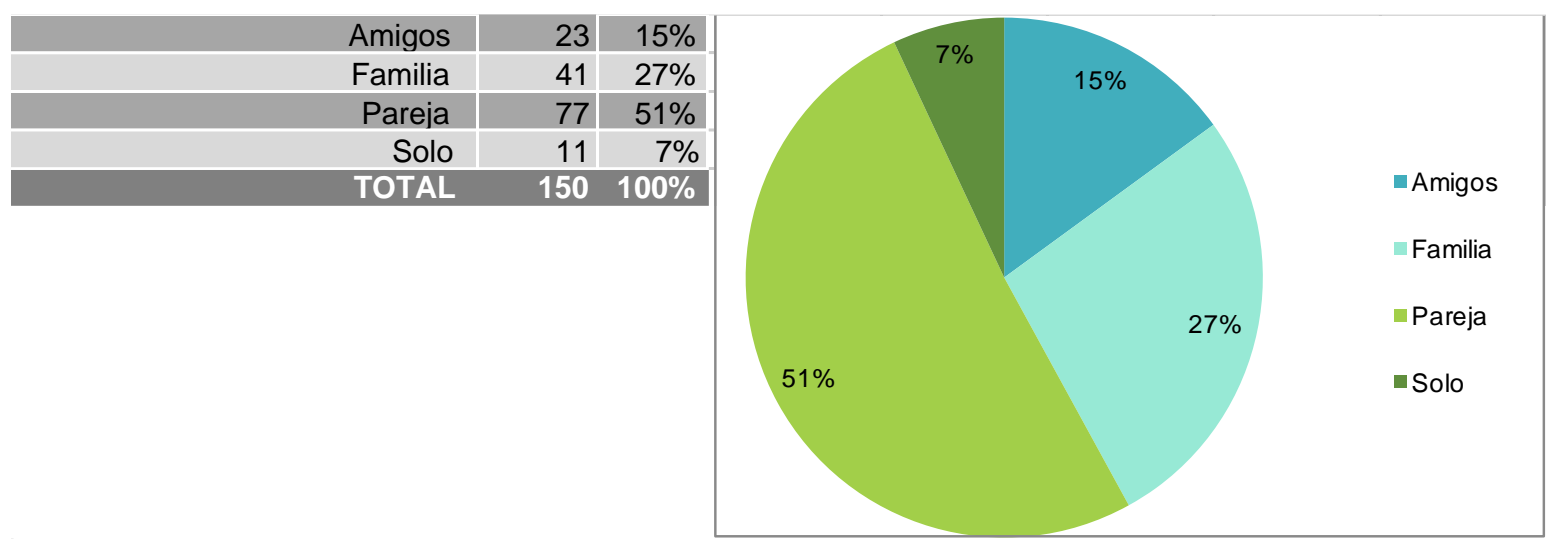

\section{Gráfica No4: Grupo de visitantes.}

Fuente: diseñado por la autora.

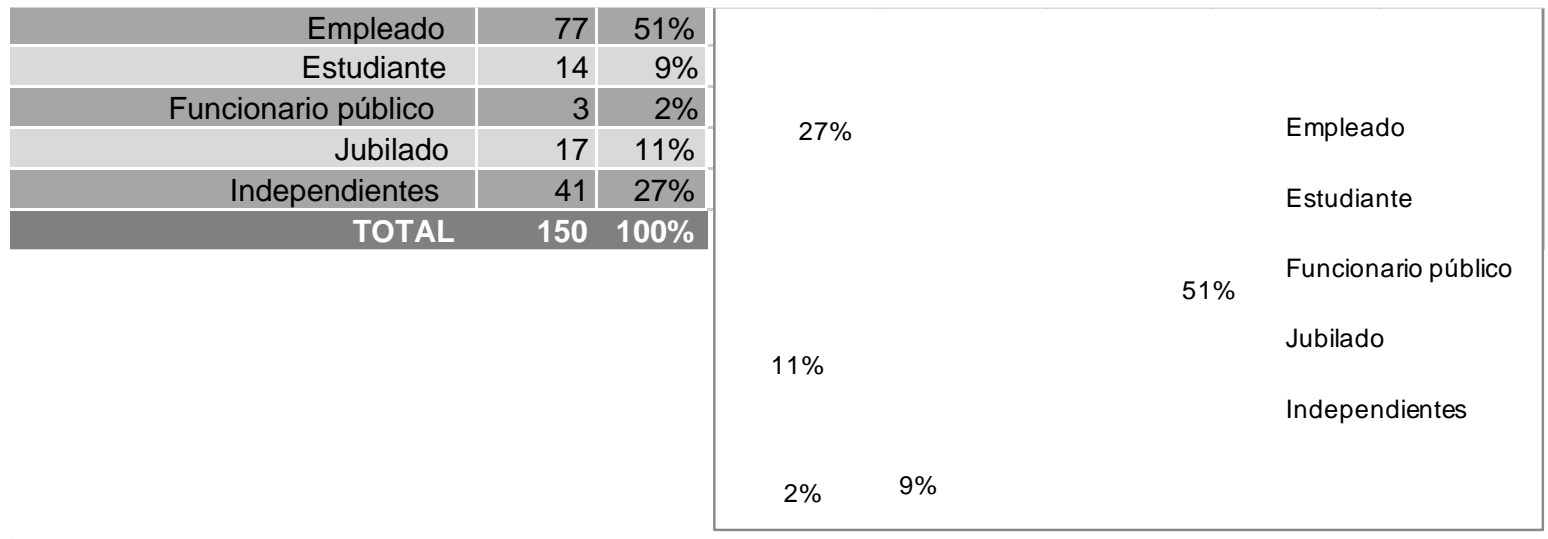

Gráfica N5: Ocupación de los encuestados.

Fuente: diseñado por la autora. 


\begin{tabular}{|r|r|r|}
\hline Hotel & 65 & $43 \%$ \\
\hline Hostal & 36 & $24 \%$ \\
\hline Cabañas & 13 & $9 \%$ \\
\hline Amigos o parientes & 23 & $14 \%$ \\
\hline De paso & 13 & $10 \%$ \\
\hline TOTAL & 150 & $100 \%$ \\
\hline
\end{tabular}
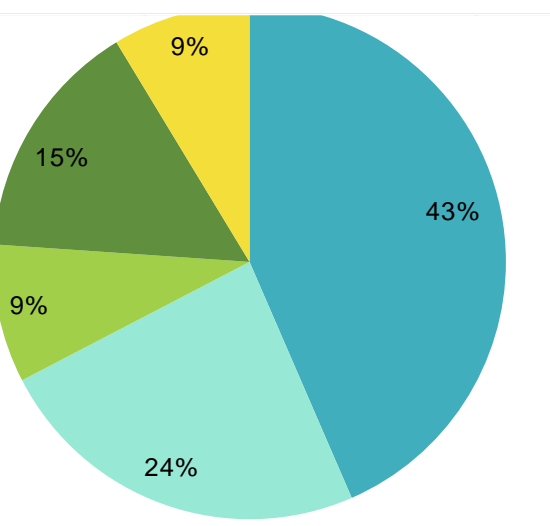

- Hotel

- Hostal

Cabañas

- Amigos o

parientes

De paso

$24 \%$

Gráfica $\mathbf{N}^{\circ}$ 6: Tipo de alojamiento.

Fuente: diseñado por la autora.

\begin{tabular}{|r|r|r|}
\hline Público & 23 & $15 \%$ \\
\hline Privado & 126 & $84 \%$ \\
\hline Alquilado & 2 & $1 \%$ \\
\hline TOTAL & 150 & $100 \%$ \\
\hline
\end{tabular}

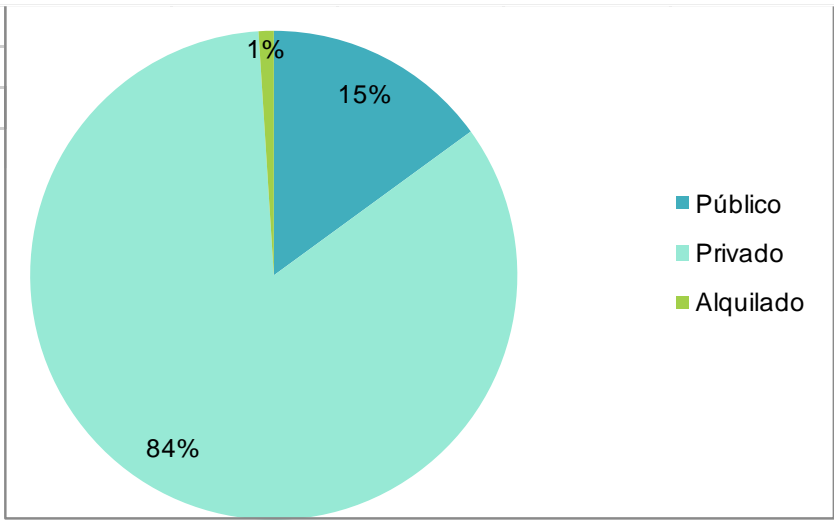

Gráfica No7: Medio de transporte utilizado.

Fuente: diseñado por la autora.

\begin{tabular}{|r|r|r|}
\hline 3 días & 75 & $50 \%$ \\
\hline 2 días & 50 & $33 \%$ \\
\hline 1 día & 12 & $8 \%$ \\
\hline Menos de un día & 14 & $9 \%$ \\
\hline TOTAL & 150 & $100 \%$ \\
\hline
\end{tabular}

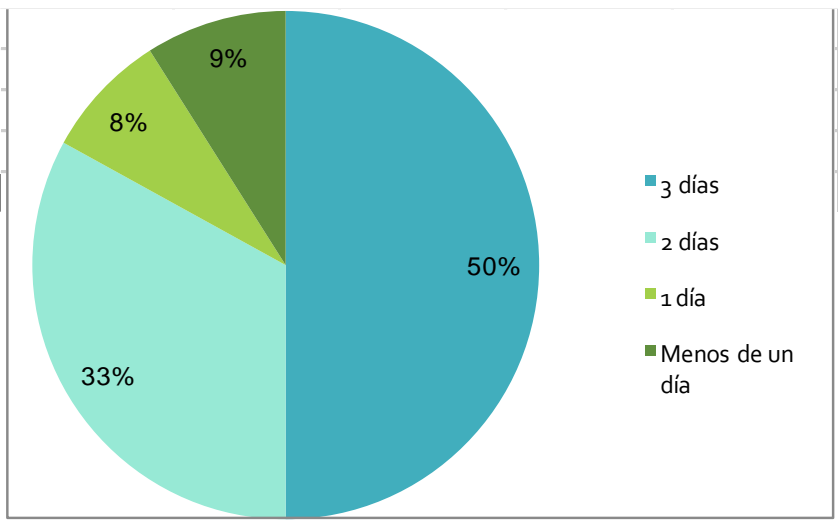

Gráfica Nº: Tiempo de estadía del encuestado.

Fuente: diseñado por la autora. 


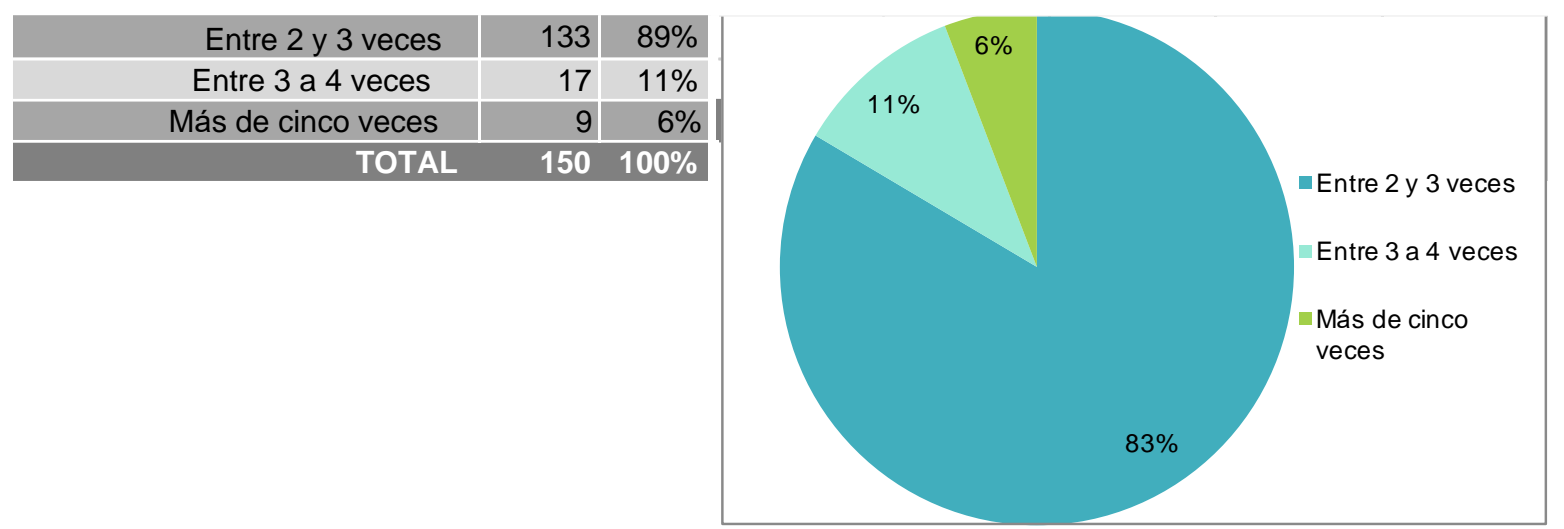

Gráfica N9: Cantidad de veces que el encuestado ha visitado Tierras Altas. Fuente: diseñado por la autora.

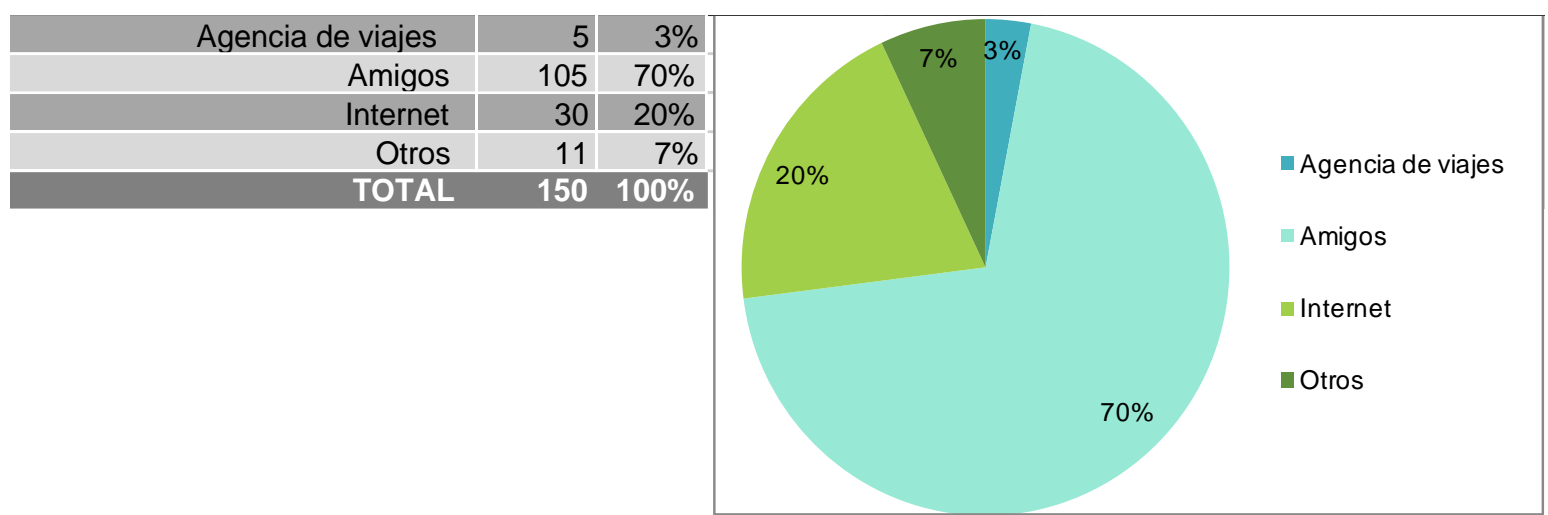

Gráfica N ${ }^{\circ} 10$ : Recomendación de la visita.

Fuente: diseñado por la autora.

\begin{tabular}{|r|r|r|}
\hline Trabajo & 8 & $5 \%$ \\
\hline Vacaciones & 105 & $70 \%$ \\
\hline Ivestigación & 3 & $2 \%$ \\
\hline Familia & 32 & $21 \%$ \\
\hline Turismo & 3 & $2 \%$ \\
\hline TOTAL & 150 & $100 \%$ \\
\hline
\end{tabular}

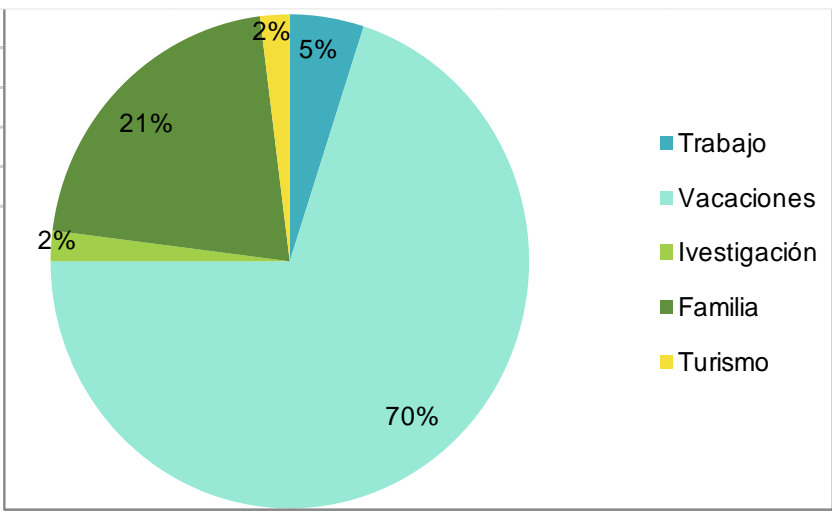

Gráfica No11: Finalidad de la visita.

Fuente: diseñado por la autora. 


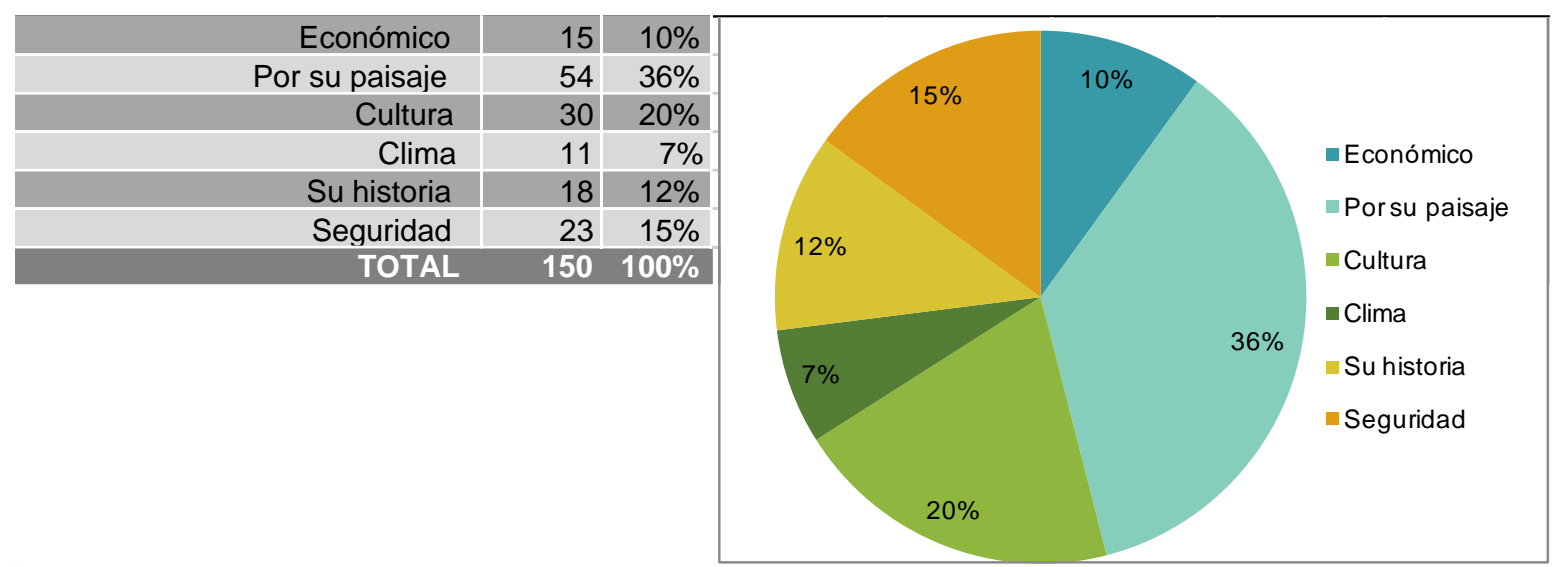

Gráfica N¹2: Criterios de elección del encuestado para elegir Tierras Altas. Fuente: diseñado por la autora.

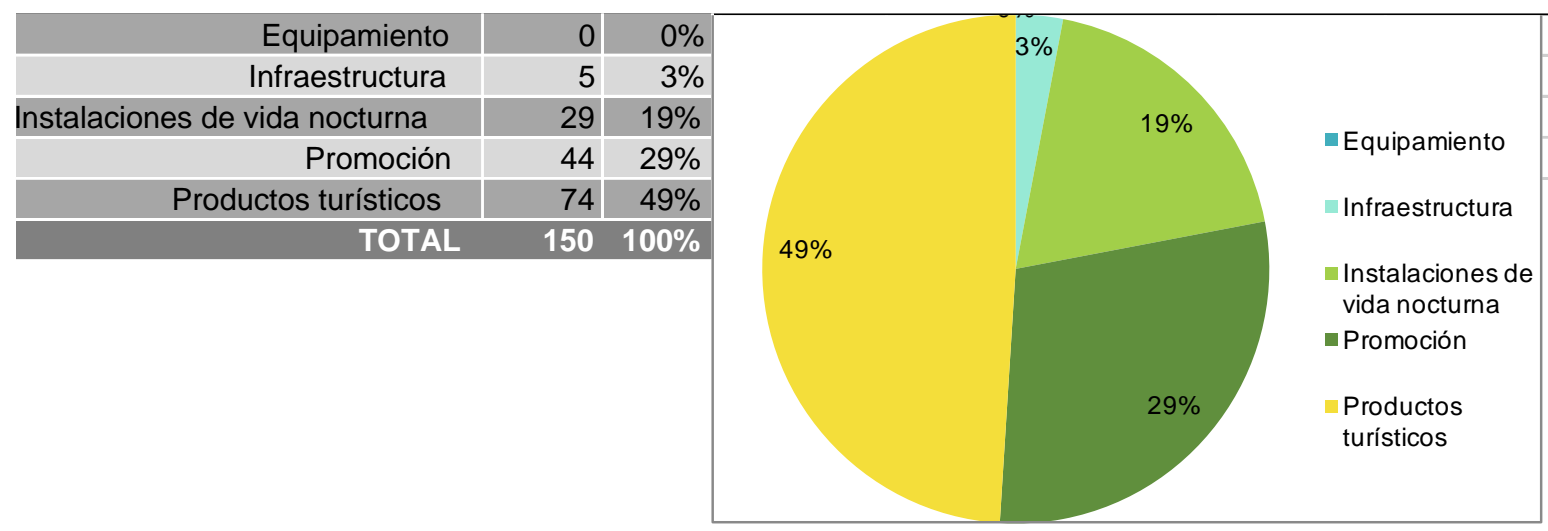

Gráfica No13: Criterios de elección del encuestado para elegir Tierras Altas. Fuente: diseñado por la autora. 
Así mismo, las conclusiones del análisis FODA, se presentan, a saber:

\begin{tabular}{|c|c|}
\hline \multicolumn{2}{|c|}{ ANÁLISIS INTERNO } \\
\hline Fortalezas & Debilidades \\
\hline $\begin{array}{l}\text { Diversidad de recursos naturales y culturales con gran potencial } \\
\text { turístico }\end{array}$ & Escasa y/o nula señalización de los recursos \\
\hline Clima fresco y agradable & Falta de capacitación en materia turística \\
\hline Buena conectividad a través de tres rutas & Inexistencia de un estudio de mercado \\
\hline Atracción paisajística & $\begin{array}{l}\text { Insuficiente accionar conjunto entre el sector público y privado para } \\
\text { favorecer la actividad turística local }\end{array}$ \\
\hline Buena accesibilidad & Escasa integración entre los prestatarios de servicios turísticos \\
\hline Tranquilidad y seguridad & $\begin{array}{l}\text { No existe conciencia turística por parte de los residentes y del } \\
\text { municipio }\end{array}$ \\
\hline Desarrollo de actividades tradicionales & $\begin{array}{l}\text { Ausencia de planificación turística y de normativas para preservar } \\
\text { los recursos naturales y culturales }\end{array}$ \\
\hline $\begin{array}{l}\text { Presencia de características que lo diferencian y/o complementan } \\
\text { de su potencial competidor }\end{array}$ & $\begin{array}{l}\text { Falta de implementación y seguimiento de políticas de desarrollo } \\
\text { turístico }\end{array}$ \\
\hline Buena predisposición de la comunidad local para recibir visitantes. & Falta de fondos y presupuesto para la actividad turística \\
\hline Valiosa historia, riqueza de sitios históricos & Escasa y/o nula señalización de los accesos a la localidad \\
\hline Imagen positiva de la población local sobre la actividad turística & Peligro en área montañosa, especialmente durante la noche \\
\hline Valiosa producción artesanal con marcada identidad cultural & $\begin{array}{l}\text { Falta de concienciación valorativa del turismo como actividad } \\
\text { económica y social }\end{array}$ \\
\hline $\begin{array}{l}\text { Producciones tradicionales (agricultura, ganadería) de importancia } \\
\text { provincial y nacional }\end{array}$ & $\begin{array}{l}\text { Pérdida de identidad, debido a su desvalorización por parte de las } \\
\text { nuevas generaciones }\end{array}$ \\
\hline $\begin{array}{l}\text { Desarrollo de producciones no convencionales que diversifican la } \\
\text { oferta }\end{array}$ & Infraestructura básica y turística insuficiente y deficiente \\
\hline Existencia de áreas de esparcimiento al aire libre & Recursos turísticos no aprovechados ni valorizados \\
\hline Buena disponibilidad de alojamiento & $\begin{array}{l}\text { Escasa flexibilidad de horarios de atención al público en los } \\
\text { comercios }\end{array}$ \\
\hline $\begin{array}{l}\text { Existencia de estancias para el desarrollo del turismo rural y } \\
\text { actividades complementarias }\end{array}$ & Inexistencia de un estudio de demanda \\
\hline $\begin{array}{l}\text { Existencia de actividad turística en la región, variados } \\
\text { acontecimientos programados durante todo el año }\end{array}$ & Falta de definición de un perfil turístico consensuado \\
\hline Existencia de la Carrera de Turismo & Presencia de productos sustitutos próximos \\
\hline \multirow{2}{*}{ Recursos humanos capacitados } & Marcada competencia con el municipio vecino de Boquete \\
\hline & Discontinuación de los proyectos turísticos planificados \\
\hline \multicolumn{2}{|c|}{ ANÁLISIS EXTERNO } \\
\hline Oportunidades & Amenazas \\
\hline $\begin{array}{l}\text { Fragmentación de las vacaciones escolares, y políticas nacionales } \\
\text { que promueven el crecimiento del turismo interno }\end{array}$ & \multirow{8}{*}{ Carencia de apoyo a proyectos turísticos por parte del municipio } \\
\hline Alto flujo de turistas & \\
\hline Reconocimiento del valor simbólico de las artesanías & \\
\hline $\begin{array}{l}\text { Nuevos perfiles de turistas: lugares pocos congestionados y un } \\
\text { mayor contacto con la naturaleza y la cultura local. }\end{array}$ & \\
\hline $\begin{array}{l}\text { Búsqueda por parte de los turistas de conocer lugares diferentes a } \\
\text { los de su entorno habitual (mayor influencia de turistas } \\
\text { provenientes de la ciudad capital de Panamá) }\end{array}$ & \\
\hline Población mayoritariamente joven & \\
\hline Posibilidad de articularse con otros destinos turísticos de la región & \\
\hline Localidades vecinas con atractivos turísticos similares & \\
\hline
\end{tabular}

\section{Discusión}

Los resultados nos conducen a una planificación estratégica dado que la misma es vital para el desarrollo económico y social de cualquier territorio, por tanto es parte del diagnóstico de la 
situación, con él se propone un modelo deseado de territorio, se fijan objetivos a través de un sistema de participación, se señalan las líneas de actuación, se fomenta la acción conjunta y consensuada de los principales agentes económicos y políticos, y trata de conseguir la adhesión de la ciudadanía y de los agentes institucionales, económicos y sociales, por lo que para ello se estructuran formas organizativas colegiadas y el desarrollo de mecanismos de comunicación y mercadeo.

Al respecto, (Poon, 1998; citado por Gandara, 2003, p.113), estima que "en los lugares donde la comunidad local no participa ni siente los beneficios del turismo, no están seguros ni los turistas, ni el área del entorno, ni la actividad turística". En tanto que "se destaca como denominador común de la planificación estratégica, la participación de la población local como actores claves y protagonistas del proceso de planificación” (Morales, 2016, p.10).

Morales (2016) explica que es importante tomar en cuenta que los procesos de planificación participativa son herramientas que permiten ver más allá y tener visión de futuro, pero no son fórmulas para la solución de problemas.

Es así como queda totalmente establecido como cierto el planteamiento de Corragio (1999), cuando afirma, que "la ciudad o municipio, como ámbito de desarrollo local tiene que atender al logro de tres grandes desafíos: competitividad, gobernabilidad y un desarrollo humano sustentable.

Y para sustentar este planteamiento, el anterior autor enfatiza con que "es importante que todo proyecto de desarrollo se fije a través de la perspectiva del beneficio de la comunidad para luego determinar la competitividad y la gobernabilidad que se adapte al modelo" (Corragio, 1999).

En el distrito de Tierras Altas la actividad turística debe estar orientada a la gestión de los recursos que satisfagan las necesidades económicas, sociales y ambientales de la población, respetando la integridad cultural, los procesos ecológicos, la diversidad biológica y el trabajo en equipo.

Por lo que su planificación debe ser basada en las expectativas de los visitantes y las necesidades de la población y considerada una herramienta de gestión para la toma de decisiones a cargo de sus autoridades; que permita orientar los recursos disponibles al cumplimiento de objetivos estratégicos, al medir el desempeño y al realizar acciones correctivas con la finalidad de fomentar el desarrollo turístico sostenible.

En tanto que las políticas para el desarrollo turístico de Tierras Altas deben orientarse bajo un principio de desarrollo local, en donde desarrollo del turismo debe lograrse a través de la participación ciudadana.

Según la evaluación interna realizada en el municipio de Tierras Altas, su actividad turística cuenta con una respuesta promedio frente a factores externos que impactan en la comunidad, aunque aún dicha actividad sigue siendo débil.

Tomando en consideración el crecimiento de flujo turístico del distrito de Tierras Altas y su participación en el mercado, sus atractivos turísticos "estrella" son los parques La Amistad y Volcán Barú, seguido de las diferentes fincas de agroturismo, y en tercer lugar la gastronomía. 
El plazo propuesto para la ejecución de las acciones del Plan Estratégico Turístico es de 7 años, de manera que se evite mezclar con intereses políticos, por lo que se sugiere la conformación de un Comité de Turismo para su evaluación y control, y una asignación presupuestaria razonable.

\section{Recomendaciones}

El municipio, como principal entidad distrital, debe incorporar medidas para fomentar la justicia y equidad en la distribución de ingresos, generación de empleo y prestación de servicios, como también mantener un respeto por la comunidad y sus manifestaciones socioculturales.

Fomentar la inversión pública-privada en sectores con alto potencial de generación de empleo y enlaces productivos internos, así como la inversión social, que fortalezca, entre otros, las capacidades de empleabilidad y emprendimiento, así como las especificidades de género y generacionales, en los ámbitos de influencia en el campo laboral.

Implementar sistemas de incentivos y fomento a la inversión privada intensiva en empleo, que, además, genera riqueza y la distribuye mejor, como el turismo comunitario, de naturaleza, de deporte y de cultura y gastronomía.

Acoger nuestra propuesta de planificación estratégica que a continuación presentamos la cual se resume en programas y proyectos producto del análisis, diagnóstico y talleres participativos orientados a lograr el desarrollo de la actividad turística en Tierras Altas. En beneficio de los pobladores, el uso responsable de sus atractivos turísticos naturales y culturales, la economía local sostenible y la satisfacción de las expectativas de los visitantes.

\section{Programa 1: La Planificación turística}

\section{Programa 2: Mejoramiento Urbano y Desarrollo de la Planta Turística}

- Proyecto A: Camping Municipal

- Proyecto B: Terminal de Ómnibus

- Proyecto C: Señalización en ruta y de los recursos

\section{Programa 3: Formación de Recursos Humanos}

- Proyecto A: Capacitación: La Cultura de la Hospitalidad

- Proyecto B: Taller Desarrollo Turístico Municipal

- Proyecto C: Incorporación de contenidos sobre turismo y protección ambiental en los espacios curriculares de las instituciones educativas de la localidad

- Proyecto D: Curso de Manipulación de Alimentos, Práctica de Higiene y presentación de alimentos y bebidas.

- Proyecto E: Capacitación de emprendimientos turísticos 
Programa 4: Conservación y preservación del medio ambiente

\section{Programa 5: Gestión Ambiental}

- Proyecto A: Uso y Promoción de energías alternativas

- Proyecto B: Gestión de Residuos

- Proyecto C: Educación Ambiental

Programa 6: Promoción y Difusión Turística

- Proyecto A: Creación de Marca

- Proyecto B: Difusión on line

- Proyecto C: Revista de información turística

- Proyecto D: Video Marketing

Programa 7: Capital Local

- Proyecto A: La oportunidad del empleo local.

- Proyecto B: Promoción de las inversiones.

Programa 8: La estructura político-institucional del municipio

- Proyecto A: Gestión Turística del Municipio

- Proyecto B: Creación de un Ente Turístico Público-Privado

Programa 9: Turismo Histórico-Cultural

- Proyecto A: Conociendo mi Distrito

- Proyecto B: Gira al Sitio Barriles.

Programa 10: Turismo de Aventura

- Proyecto A: Rafting en el Río Chiriquí Viejo

- Proyecto B: Paseos a caballo.

En la marcha con la ejecución de este:

El distrito de Tierras Altas debe generar vínculos con la universidad, para el levantamiento de la información necesaria de los aspectos turísticos de la región, y así actualizar y alimentar este Plan Estratégico.

Iniciar el proceso de control del ingreso de visitantes y establecer un punto de registro.

Contemplar la creación de paneles interpretativos sobre la naturaleza que abunda en el distrito de Tierras Altas, así como zonas de descanso, puntos de agua en las rutas de larga caminata, entre otras zonas de interés turístico. 
Crear zonas de camping acondicionadas, cestos para la disposición correcta de la basura, servicios sanitarios, y señalización amigable con el escenario paisajístico.

Trabajar directamente con la población en algunos talleres de integración comunal, para que les permita crear proyectos turísticos que se ajusten a su realidad y necesidades.

Sensibilizar a la población de la importancia del turismo y de su impacto en su calidad de vida.

Concienciar a los turistas en la protección y conservación de sus paisajes naturales, haciéndoles entender que su visita es un aporte al desarrollo de la comunidad.

Mejorar los servicios de hospedaje, y crear mayor oferta en los de restauración y entretenimiento.

Crear fuentes de financiamiento en coordinación con la población, para reinvertir en infraestructura u otras actividades de índole turística.

Fomentar la creación de un organismo mixto que fortalezca el desarrollo local con el apoyo del sector privado.

\section{Bibliografía}

- Acerenza, Miguel (1997); "Reflexiones sobre la Planificación del Turismo en Latinoamérica" Aportes y Transferencias, Mar del Plata: CIT, año 1 volumen 2.

- Alburquerque, Francisco. (1996). "Fomento productivo municipal y gestión del desarrollo económico local”. ILPES, Santiago de Chile.

- Andreu, Marta Nel-Lo y PÉREZ ALBERT, Yolanda. (2007). "La Política Turística en Panamá". Murcia, España: Universidad de Murcia. Cuadernos de Turismo No20, 2007; pp.199-221.

- Arocena, José. (1995). "El desarrollo local. Un desafío contemporáneo”. Ed. Nueva Sociedad.

- ATP. (2017). "Plan Maestro de Desarrollo Turístico Sostenible 2007-2020 “. Panamá: Autoridad de Turismo de Panamá. http://www.atp.gob.pa/programas/plan-maestro-de-desarrollo-turisticosostenible-2007-2020

- Bernet, Josep. (2005). "Destinos turísticos de éxito". Madrid, España: Ediciones Pirámide.

- Borja, J. Y Castells, M. (1997). "Local y Global. La gestión de las ciudades en la era de la información”. Madrid: Taurus.

- Corragio, J. (1997). “Descentralización, el día después...”. Buenos Aires, CBC-UBA.

- FASABI HUAMÁN, Karen Inés. (2014). "Formulación de un Plan Estratégico Turístico para el distrito de San Jerónimo de Surco que fomente su Desarrollo Turístico Sostenible”. Lima, Perú: Universidad Nacional Mayor de San Marcos, Facultad de Ciencias Administrativas. 
- Gandara, J. M. G. (2003). "La sostenibilidad de los destinos turísticos urbanos. In Molina, S. (edit), Organizaciones del Tercer Sector en el Turismo”. Turismo 1, REDES, Ciudad de México, pp. 91-118.

- Garrido, Francisco Javier. (2002). "Planificación participativa para el desarrollo local”. Madrid: CIMAS. http://www.redcimas.org/wordpress/wpcontent/uploads/2012/08/m_JGarrido_PLANIF.pdf

- Gobierno Nacional. (2015). "Ley Nº6 (De jueves 29 de octubre de 2015), que reforma la Ley 37 de 2009, que descentraliza La Administración Pública, y dicta otras disposiciones". Panamá: Gaceta Oficial Digital, viernes 30 de octubre de 2015. https://www.gacetaoficial.gob.pa/pdfTemp/27901_A/GacetaNo_27901a_20151030.pdf

- Guzman Ramos, A. Fernández, G. (2002). "El turismo desde la geografía". Biblio 3W, Revista Bibliográfica de Geografía y Ciencias Sociales, Universidad de Barcelona, Vol. VII, $\mathrm{n}^{\circ}$ 365. http://www.ub.es/geocrit/b3w-365.htm

- Hernández Sampieri, Roberto et al. (1997). "METODOLOGÍA DE LA INVESTIGACIÓN”, 4ta Ed. México DF: McGraw Hill.

- Leno Cerro, Francisco. (1983). “Técnicas de Evaluación del Potencial Turístico”. Madrid: Ministerio de Industria, Comercio y Turismo. Libros sobre Turismo, Nº 2 .

- Madruga Torres, Ana Gloria y FORTEZA ROJAS, Saimelyn. (2012). "Sistema Productivo Turístico y Desarrollo Local". Cuba: Revista TURyDES de investigación en turismo y desarrollo local, Vol 5, No 12. http://www.eumed.net/rev/turydes/12/mtfr.html

- Morales, Aldana. (2016). "Estrategias de Desarrollo Turístico en la ciudad de Belén, Catamarca, a partir de la Planificación Participativa”. Argentina: Universidad Nacional del Sur, Departamento de Geografía y Turismo.

- Paul, Samuel. Community Participation in Development Projects. The World Bank Experience. [En línea]. Washington, D.C, 1987, http://www-sworldbank.org

- "Programa de Desarrollo Turístico de la Provincia de Chiriquí, Panamá. (2012). Panamá: Organización Mundial del Turismo (OMT), Programa Conjunto del Fondo para el Logro de los Objetivos del Milenio, Autoridad de Turismo de Panamá.

- Schulte, Silke. (2003). "Guía conceptual y metodológica para el desarrollo y la planificación del sector turismo". Serie Manuales. ILPES. CEPAL. Santiago de Chile.

- Silva, Iván. (2003). “Metodología de Elaboración de Estrategias de Desarrollo Local: Dirección de Desarrollo Local y Regional”. Santiago de Chile: CEPAL/ILPES.

- Steiner, George A. (2014). “Planeación Estratégica: lo que todo director debe saber”, 2da Edición. México DF: Grupo Editorial Patria.

- "Varisco, Cristina. (2007). "Sistema Productivo Turístico y Desarrollo Local". Viña del MarChile: Ciencias Sociales Online, Julio 2007, Vol. IV, No. 2. http://nulan.mdp.edu.ar/432/1/00457.pdf 
- Vásquez Barquero, A. (1988). "Desarrollo local. Una estrategia de creación de empleo" Madrid, Editorial Pirámide.

- Zingoni, J. (2007). "Plan estratégico participativo de Desarrollo turístico sustentable del Partido de Patagones". Carmen de Patagones. 